\title{
JUVENTUDE E CULTURA SURDA
}

Ana Regina e Souza Campello ${ }^{\mathrm{i}}$

Resumo: Este artigo reflete sobre juventude e Cultura Surda buscando verificar, através de observação de campo da própria pesquisadora, o processo de criação e de transformação de gírias em sinais por meio do uso por jovens Surdos. A criação de sinais específicos é um fato que gera novas gírias na comunicação entre eles, como marca identificatória do grupo. A partir da análise, constatou-se que as gírias em grupo tornam-se essencial para a preservação desse e de sua cultura, o que é ininteligível para a compreensão geral da língua cotidiana para ouvintes.

Palavras-chave: Jovens Surdos; Libras; Cultura Surda.

\section{LA JUVENTUD Y LA CULTURA SORDA}

Resumen: Este artículo reflexiona sobre la juventud y la Cultura Sorda e intenta verificar, a través de la observación del campo llevada a cabo por la investigadora, el proceso de creación y transformación de argots en señas mediante el uso de los jóvenes sordos. La creación de señas específicas es un hecho que genera nueva jerga en la comunicación entre ellos, como huella identificativa del grupo. A partir del análisis, se encontró que las jergas en un grupo se convierten en esenciales para la preservación de este y su cultura, lo que es ininteligible para la comprensión general del lenguaje cotidiano para los oyentes.

Palabras-clave: Jóvenes Sordos; Libras; Cultura Sorda.

\section{Considerações iniciais}

Com a oficialização da Língua de Sinais Brasileira, denominada como Libras ${ }^{\mathrm{ii}}$, esta vem alcançando, aos poucos, o reconhecimento da importância de seu uso no Brasil. A Libras é o meio legal de comunicação e expressão da pessoa Surda ${ }^{\text {iii }}$ brasileira, bem como responsável pelos avanços tecnológicos que permitem as trocas de conhecimento, principalmente por meio das narrativas e gírias em Libras existentes, criadas e registradas pelos próprios Surdos que objetivam, entre outras coisas, difundir sua língua, identidade e cultura, nas escolas.

Para Geertz e Schneider (1973, apud HONORIO, s/d): cultura deve ser considerada não um complexo de comportamentos concretos, mas um conjunto de mecanismos de controle(...) para governar o comportamento. Portanto, a missão dos professores, os usuários ou Intérpretes de Língua de Sinais Brasileira é tentar entender que não é a interpretação e 
explicação dos fatos de forma isolada, e sim a importância do conjunto, como ele está sendo vivido e transmitido, perpetuado pela adaptação de quem chega e se insere na urdidura dos significados, sejam eles julgados corretos, ridículos, inocentes, cruéis...” (HONÓRIO, s/d).

A respeito da Juventude, os autores Sarriera, Câmara e Berlim (2006, p. 21, apud MABDELLI et ali, 2011) denominam como uma condição social, compreendida:

[...] como um conjunto de estatutos que assume e de funções sociais que desempenha uma determinada categoria de sujeitos na sociedade, então, no caso dos jovens, determinada pela situação de transição da dependência familiar à plena autonomia social.

E faz parte da cultura jovem a utilização das gírias. A gíria é derivada de contribuições variadas da língua comum, no caso da Libras. É muito utilizada para camuflar as expressões, a liberdade de expressar ou licença poética de cada Surdo/a. Isso é usado tanto para criar novas formas de se ler o mundo dos jovens quanto para misturar sinais no intuito de comunicar a mensagem poética, discursiva e gírias em sinais com criatividade. A produção dialoga com os espaços de sua criação, de acordo com o contexto social e educacional.

Sob essa perspectiva, o presente artigo traz uma análise, com observações de campo, de como os sinais ou gírias elaborados pelos jovens Surdos podem contribuir como registro de um instrumento de uso comunicativo e de comunicação em grupo, de acordo com a Cultura Surda. Também contribui para o crescimento lexical da Libras, tanto para jovens surdos quanto para professores ou usuários ouvintes no contexto educacional.

\section{Juventude e Cultura Surda: a simbiose comunicativa}

A juventude, segundo Ozella e Aguiar (2008, apud MADELLI et ali, 2011), conforme a concepção de juventude adotada por eles:

[...] compreende os jovens sob um olhar desnaturalizado. Assim, os significados de adolescência são construídos na relação dialética objetividade/subjetividade, não havendo uma adolescência natural. O significante "adolescência" não é negado, mas também não é compreendido como uma fase de desenvolvimento, ou como universal. O interesse científico parte da compreensão de como a adolescência é constituída historicamente, em vez de compreender o que ela é, na tentativa de criar uma identificação quase natural. 
Os jovens Surdos constroem a juventude de acordo com a língua de sinais e cultura surda, como base comunicativa e de expressão. É um espaço de "conforto linguístico" (SILVA, 2000, apud SCHMITT, 2005, p. 96): A identidade e a diferença têm a ver com atribuição de sentido ao mundo social e com disputa e luta em torno dessa atribuição.

Trata-se de uma exigência dos Surdos, dentro dos Estudos Culturais, que lutam por seus direitos de acesso ao espaço da vida escolar, estimulando uma nova construção de identidade no espaço linguístico/cultural na educação de surdos, diferentemente da Associação de Surdos, onde o espaço linguístico e cultural já é respeitado em todos os aspectos.

Aparentemente, a construção identitária e cultural do Surdo não acontece nas suas residências, onde a maioria dos jovens Surdos (aproximadamente 95\%) é oriunda de pais ouvintes não usuários de Libras que lidam, todos os dias, com um filho surdo que não fala português, um quase estrangeiro ${ }^{\text {iv }}$, que a todo tempo está próximo fisicamente e distante linguisticamente (SANTOS FILHO; OLIVEIRA, s/d).

Esses Jovens Surdos buscam seus semelhantes que lidam com a mesma língua e cultura, apesar de ter identidades diferentes. Segundo Gladis Perlin (2002):

As diferentes identidades Surdas são bastante complexas, diversificadas. Isto pode ser constatado nesta divisão por identidades onde se tem ocasião para identificar outras muitas identidades Surdas, ex: Surdos filhos de pais Surdos; Surdos que não tem nenhum contato com Surdo, Surdos que nasceram na cidade, ou que tiveram contato com Língua de Sinais desde a infância etc. Como dissemos, a identidade Surda não é estável, está em contínua mudança. Os Surdos não podem ser um grupo de identidade homogênea. Há que se respeitarem as diferentes identidades.

Isso mostra que, durante a construção dessas identidades, a identidade cultural sempre impera porque a língua de sinais é uma língua que os Surdos usam. Convivem com a mesma experiência visual (PERLIN; MIRANDA, 2003). A identidade surda é o ponto de partida para identificar as outras identidades Surdas. Se a identidade surda for bem elaborada, instruída e consciente, pode-se criar uma identidade política, pois esta está no centro das produções culturais.

A juventude não os impede de serem pessoas dentro da sociedade. Usam ou imitam a "moda" dos outros, carregam os celulares, usam os bonés, arriam as calças atrás, mostrando as cuecas ou as calcinhas, usam as camisas largas, imitam os penteados dos "famosos", são 
"piriguetes", dançam e acompanham os ritmos musicais dos outros, assim como todos os jovens.

No ambiente escolar e na associação de Surdos, que são os pontos de identificação e de empoderamento, os Surdos, ao criar novas gírias ${ }^{\mathrm{v}}$ em sinais, passam a constituir como marca identificatória do grupo. Mais de uma criação para empoderar a língua de sinais brasileira.

$\mathrm{Na}$ área da psicologia, pode-se argumentar bem a respeito do "processo identificatório" que surge na simbiose comunicativa. Costa (apud DARSIE, 2006, p. 185) explana que:

\begin{abstract}
A intenção relacional pode ser determinada pela busca afetiva, estética e comportamental, vinculadas a processos identificatórios pessoais que irão dar conformação a uma identidade coletiva, ou seja, a um conjunto de indivíduos que se agregam em determinados lugares do espaço por se identificarem em algum ponto, ou em vários que os unem, como o hábito de fumar.
\end{abstract}

É compreensível a formação que se dá dos Jovens Surdos que, consciente ou inconscientemente, tentam formar uma unidade que converta todos os pertencentes do grupo em torno uma base sólida, no caso com a língua de sinais, pois com essa deixam de ser excluídos dentro da sociedade.

E com este grupo e sua língua de sinais, dá-se o ponto de fomento de neologismo em Libras, como gíria em sinais camuflada para designar aquele ou aquilo que se entende. Silva (2015, p. 112) salienta que:

[...] o estudo descritivo das gírias na forma como a comunidade os utiliza apresenta duas diferentes tipologias (internas e externas) onde, (...) têm possibilidade de formar a comunicação durante o ato da fala. Da gíria interna, esta se caracteriza pelo uso sigiloso e sutil de eufemismo, principalmente quando se referem a assuntos mais intensos, palavrões, humor, sinais ocultos, onde espalham estes sinais para outros surdos da sua comunidade. Os sinais, muitas vezes, são resumidos ou abreviados, com sentido na construção da pragmática do grupo.

As gírias em sinais são mais utilizadas nas Associações de Surdos e nos espaços escolares onde se agrupam números de pessoas Surdas. Os sinais criados não são criações em caráter particular, e é sempre disseminado de acordo com a cultura Surda, onde todos podem compartilhar entre si, conforme Geertz (1973 apud HONÓRIO, s/d), uma vez que a cultura não é nunca particular, mas sempre pública. 
A característica da cultura é o mecanismo adaptativo, o qual prevê a capacidade que as pessoas têm de responder ao meio de acordo com mudança de hábitos, de costumes, de aquisição de conhecimentos, de construção de uma nova identidade, de adaptação às novas tecnologias, e até mais que possivelmente uma evolução biológica.

A cultura é também um mecanismo cumulativo porque as modificações trazidas por uma geração passam à geração seguinte, onde vai se transformando, perdendo e incorporando outros aspectos, como no caso da gíria em sinais, procurando assim melhorar a vivência das novas gerações.

Foi realizada uma pesquisa de campo como metodologia e o método utilizado foi a observação de campo. Pesquisa de campo, segundo Moresi (2003), é investigação empírica realizada no local onde ocorre ou ocorreu um fenômeno ou que dispõe de elementos para explicá-lo. Pode incluir entrevistas, aplicação de questionários, testes e observação participante ou não. O método utilizado foi o de observação de campo, na qual a pesquisadora se envolveu com os grupos jovens da Associação Alvorada e das informações oferecidas pelos professores Surdos e ex-alunos do INES - Instituto Nacional de Educação de Surdos.

As gírias em sinais existiam desde a década de 80 e 90 . Algumas foram extintas ou não são mais tão usadas e outras permaneceram até hoje.

Vejam as gravuras dos anos 80 (oitenta), mais especificamentea partir de 1987:

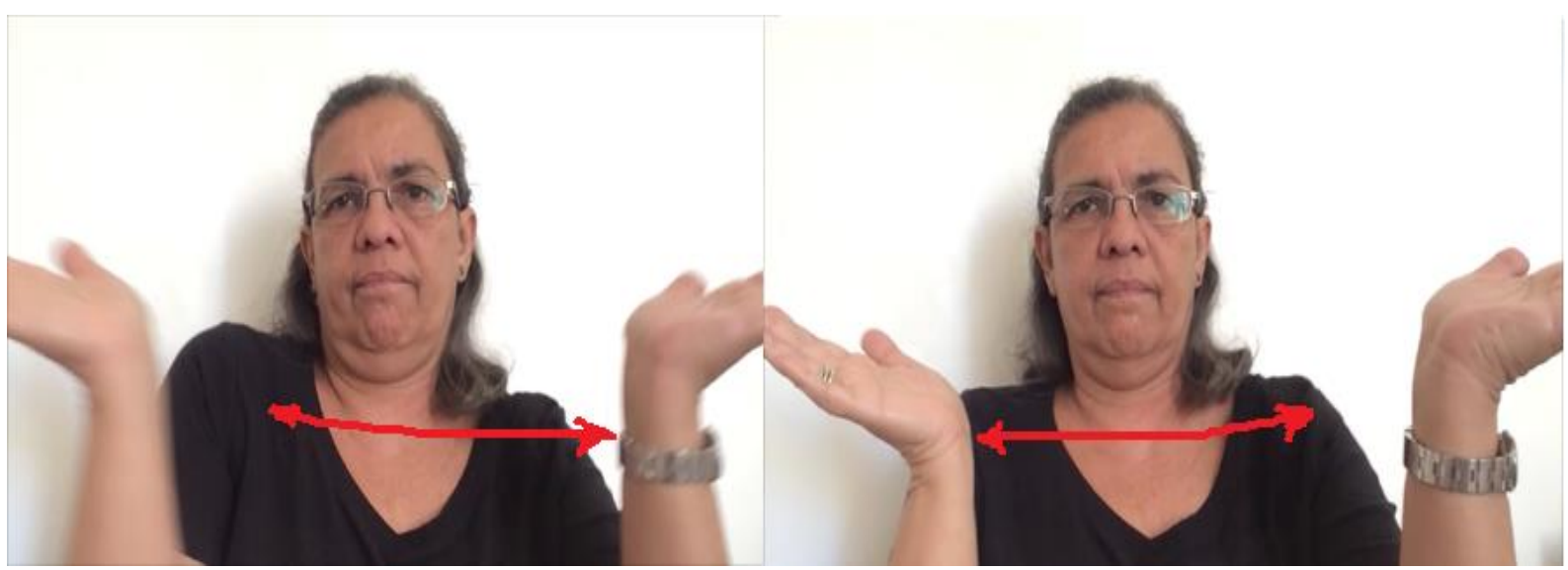

Gravura 1: tradução - "pega leve!” 


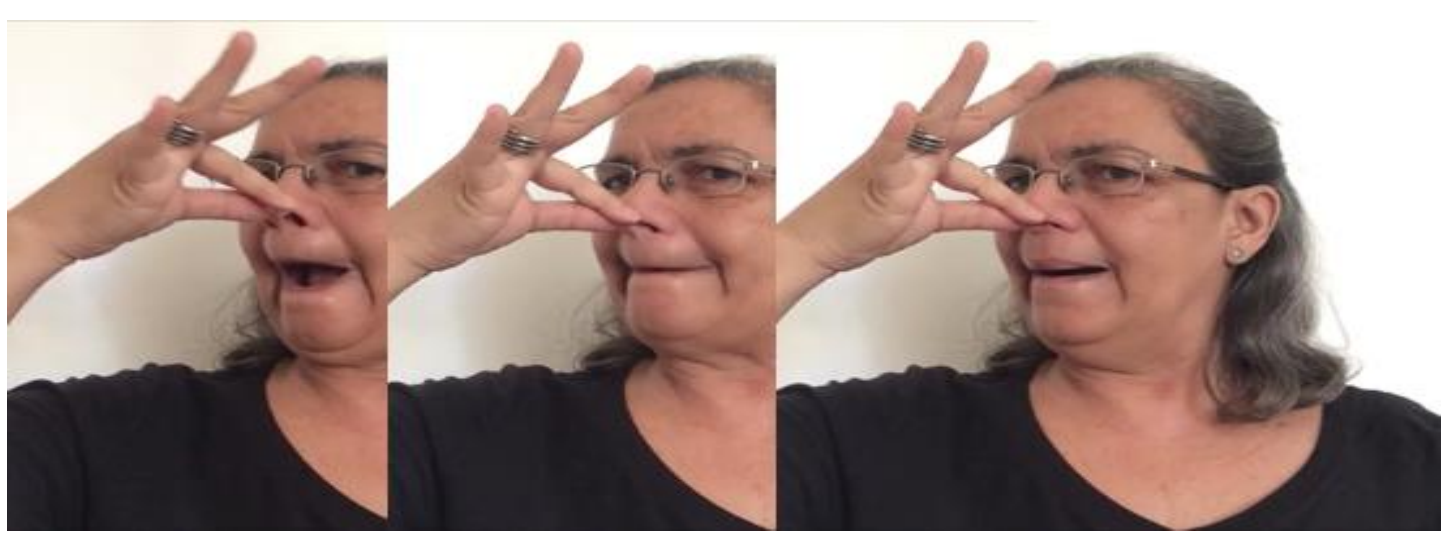

Gravura 2: tradução - "Deu tudo errado!"

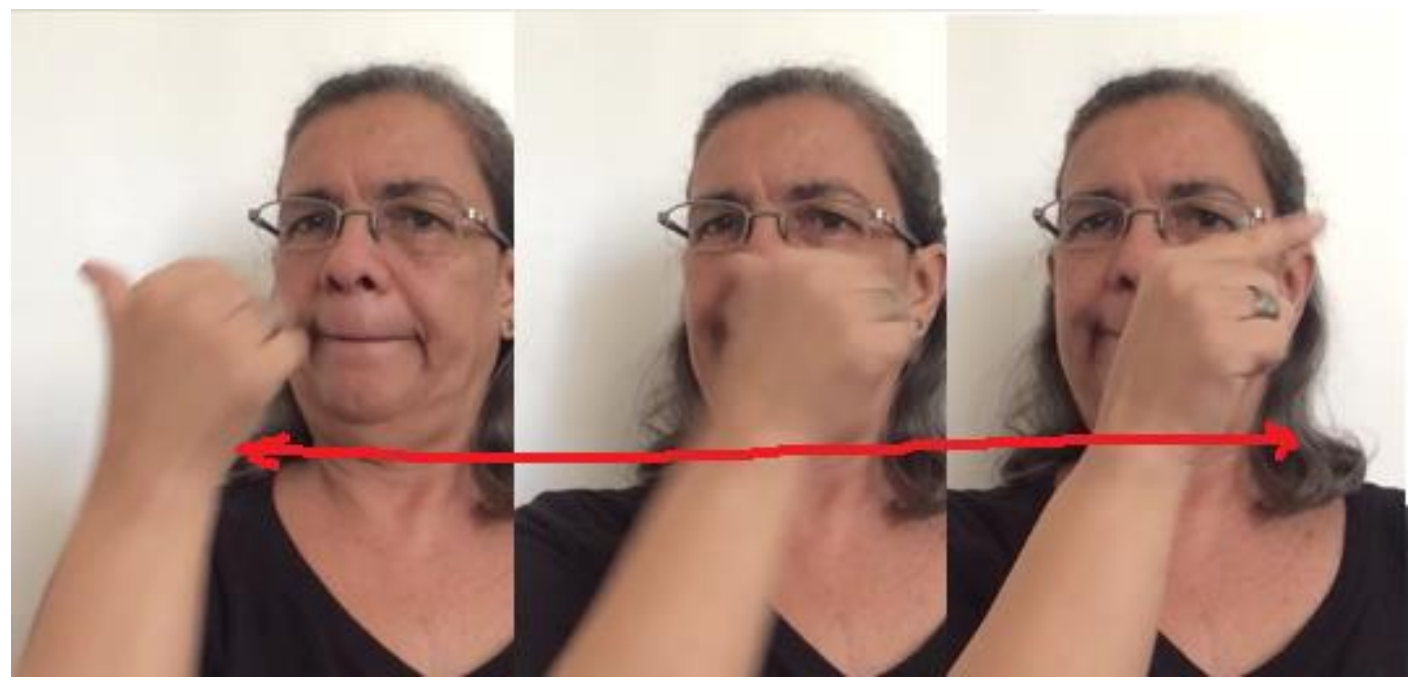

Gravura 3: Tradução - "Estragou tudo!"

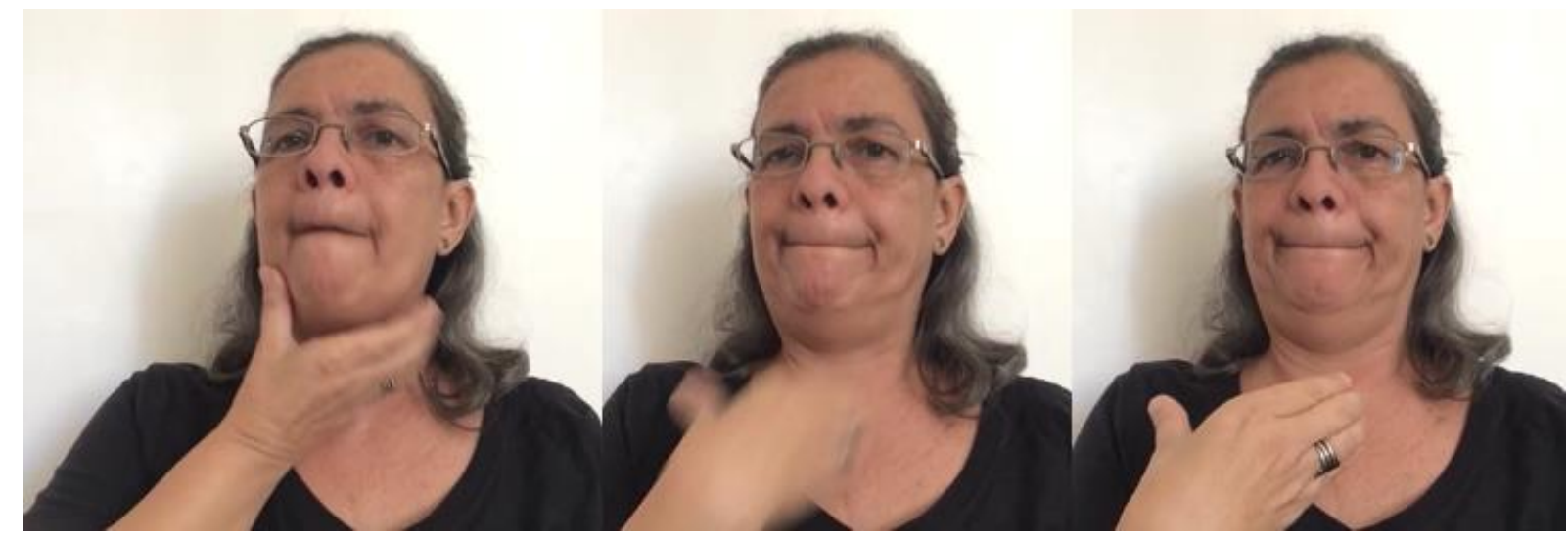

Gravura 4: Tradução - "Extravagante!”

Agora, gravuras (sianis) os anos 90, mais especificamente a partir de 1994: 

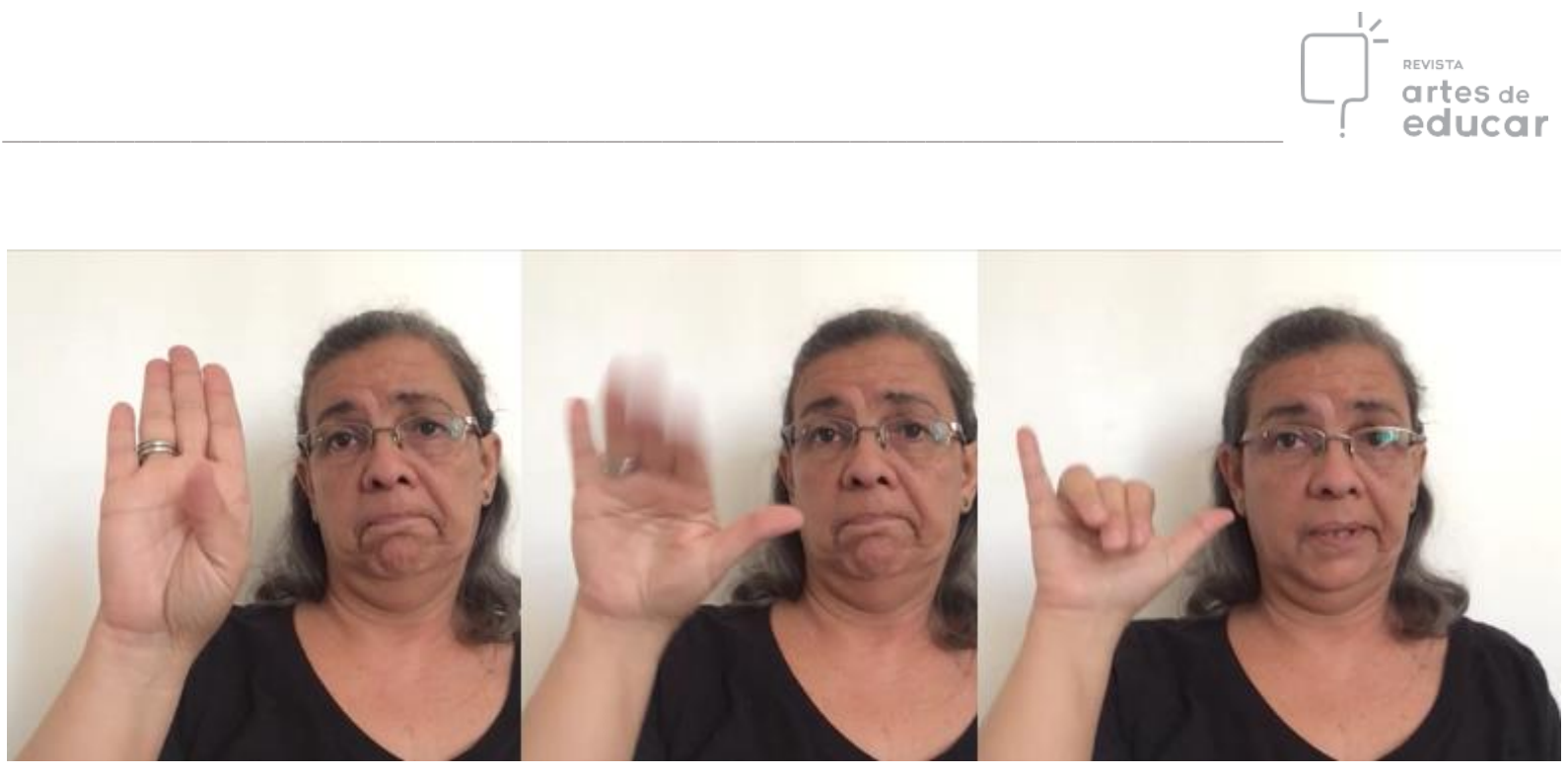

Gravura 5: Tradução - "Tadinha!"

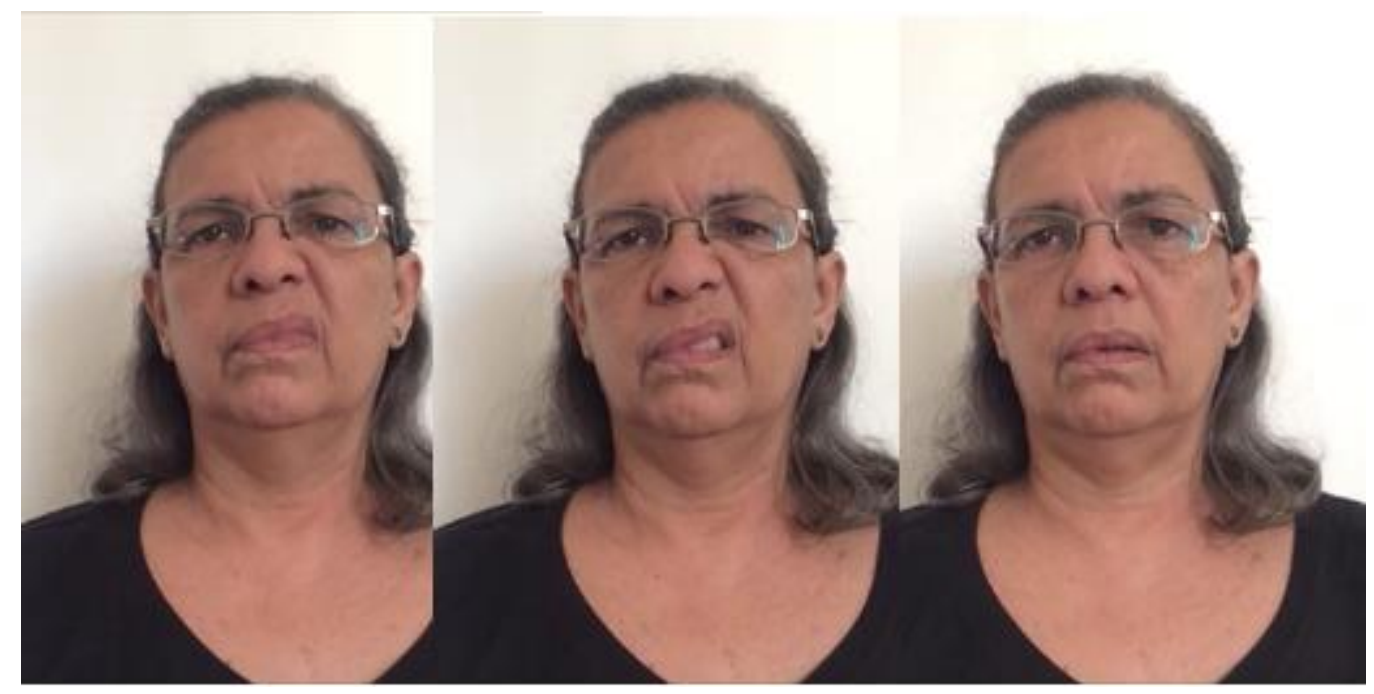

Gravura 6: Tradução - "Sei, sei, sei..."

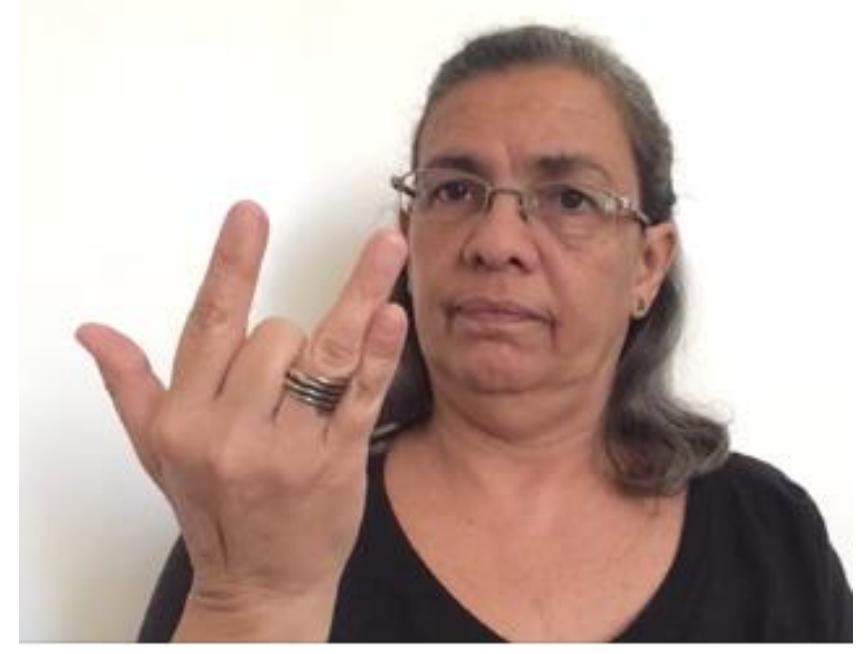

Revista Interinstitucional Artes de Educar. Rio de Janeiro, V. 2 N. 1 - pág. 104-115 (fev - mai 2016): “Artes de ser professor: práticas, criações e formações" - DOI: 10.12957/riae.2016.24888 
Gravura 7: Tradução - "Mano, amigo"

Hoje, como diz a cultura como um mecanismo e de acordo com a evolução, as gírias vão perdendo as suas configurações de mãos e acabam incorporando a minimização da mesma configuração de mãos, acompanhando o uso realizado no convívio das novas gerações.

Inicialmente, a análise apresentada era composta de 12 (doze), mas optou-se por apresentar 11 (onze) gírias em sinais. Essa escolha se deve ao intuito de preservar algumas gírias, respeitando os "segredos" dos jovens Surdos, a fim de evitar a sua "marginalização linguística".

Vejamos mais algumas gírias, abaixo:

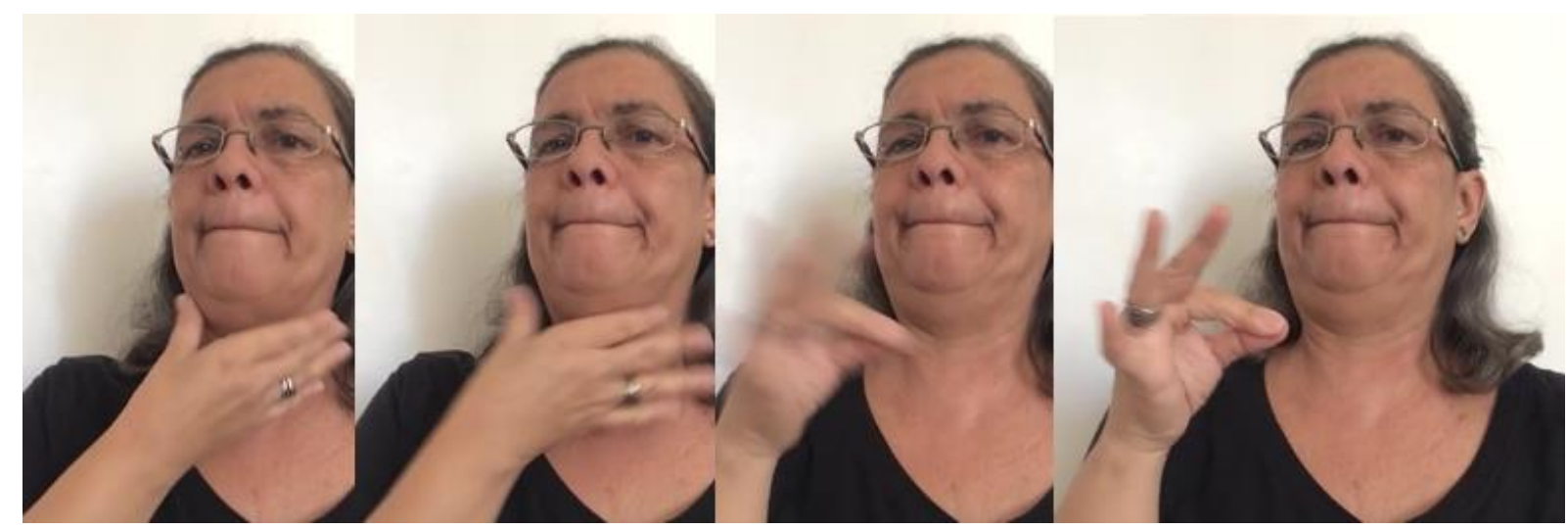

Gravura 8: Tradução - “Extravagante!”

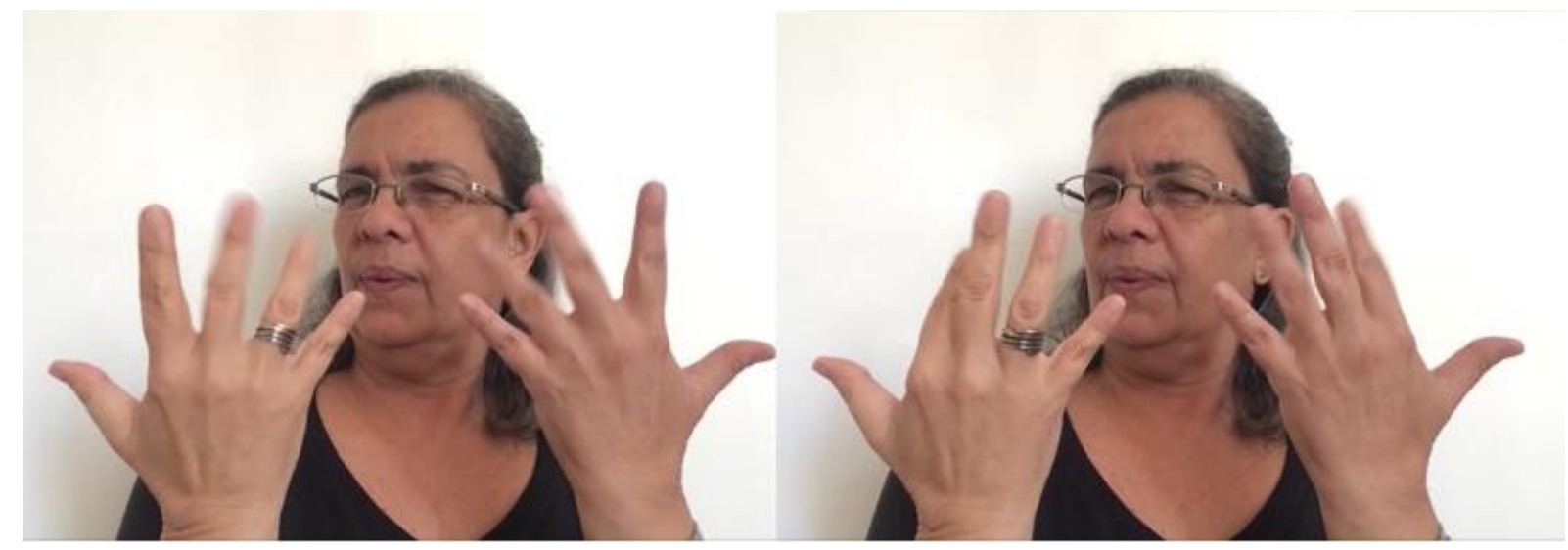

Gravura 9: Tradução - "Boa de lábia”. Também é utilizado como "senso comum”

Os jovens Surdos, por falta de informação e conhecimento, ridicularizam e marcam os Surdos-Mudos, que são aqueles que apresentam performance de "idiota" ou "otários". 


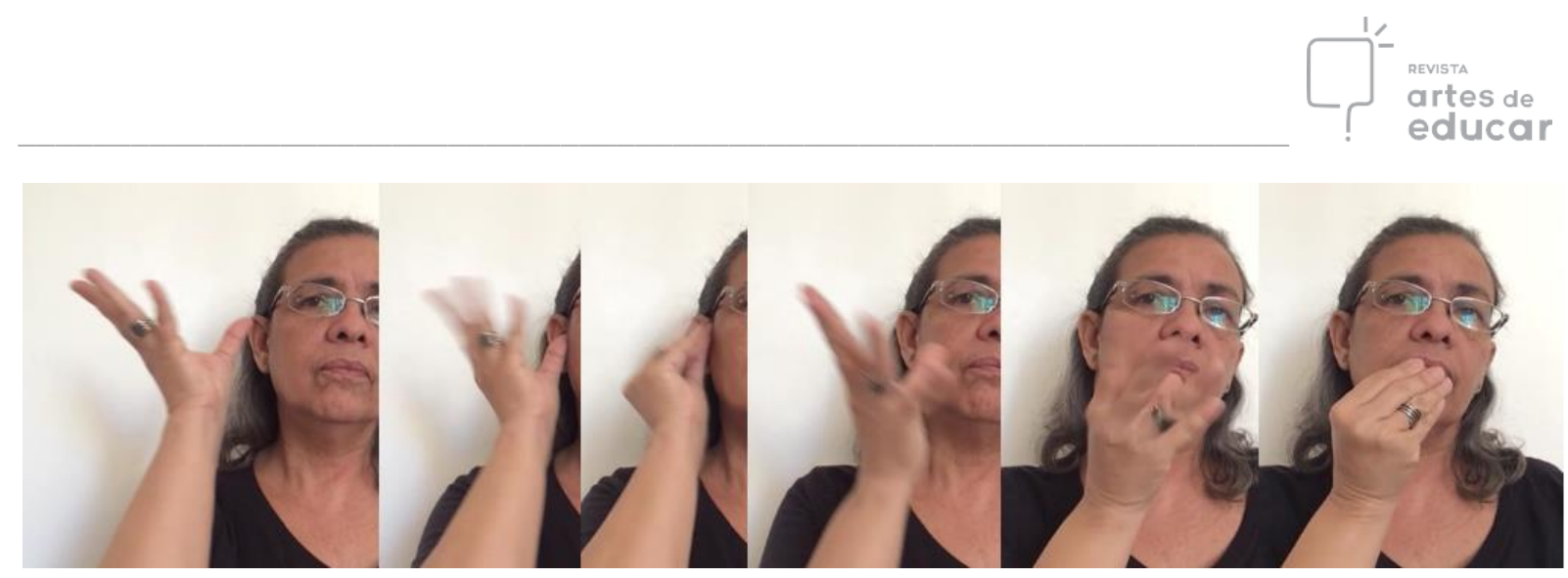

Gravura 10: Tradução - "Surdo-Mudo"

A dissertação de mestrado de Isaack Silva (2015), Gíria em Língua de Sinais Brasileira (LSB): processo e interpretação, apresentou gírias utilizadas pelos Jovens Surdos, conforme a gravura abaixo:

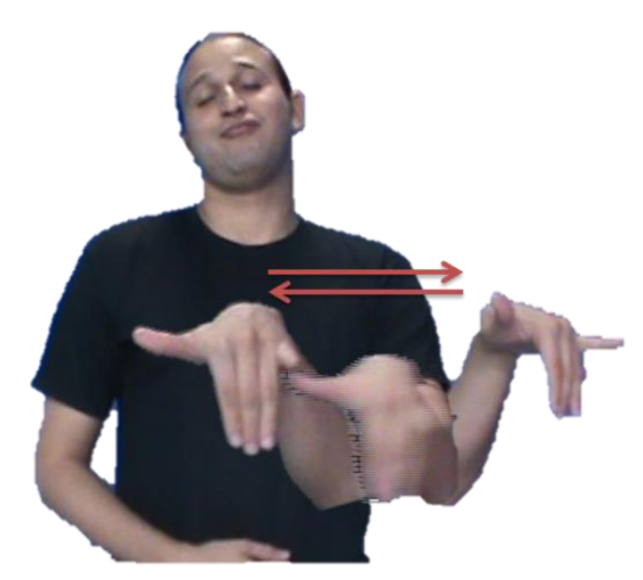

Tradução: Não se preocupe com a situação de desespero, tá ligado!?! Relaxe. Gravura 11 produzida pelo Mestre Isaack Saynour Silva (2015).

Com a influência e o contato com os Jovens Surdos da cidade de São Paulo, a gíria paulista foi incorporada na lista das gírias do Rio de Janeiro: A gíria "Tranquilo/a", cuja configuração de mãos passou a ser assim, conforme a gravura 12: 


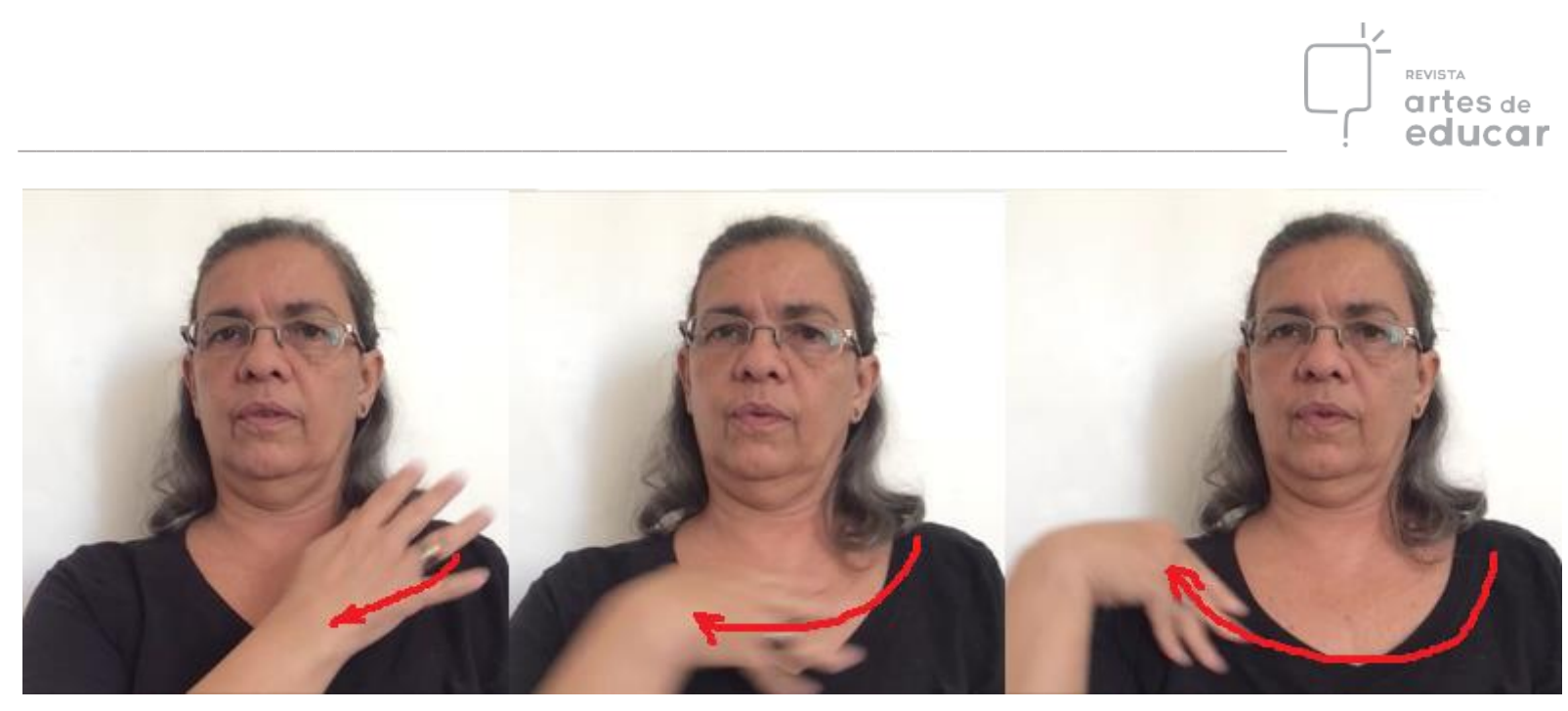

Gravura 12: Tradução "Tranquilo/a”

Percebe-se, aqui, que as relações sociais e criação de gírias em sinais, como fenômeno linguístico, se destacam como marca do "Ser Surdo", como “diferença”. É uma marca cultural da juventude Surda.

Diferença $^{\mathrm{vi}}$ é como um olhar diferenciado sobre o mundo e sua realidade... Os Jovens Surdos criam um espaço, tanto como os não-Surdos, que possibilita um deslocamento, sem um eixo centralizado, controlado e demarcatório. As cópias e imitações dos aspectos sociais, como a moda e o modo de vestir e outros comportamentos sociais são bem-vindas, mas a língua de sinais e suas gírias são inconfundíveis nos olhares dos não-surdos, assim como a gíria deles na língua falada.

Assim, o presente artigo corrobora com a afirmativa do autor Stuart Hall (1997, p. 234) ao concordar que a diferença é importante porque é essencial ao significado; sem ela, o significado não teria como existir. Sem as gírias em sinais dos Jovens Surdos e a ausência da sua diferença, eles não existiriam enquanto jovens surdos. A diferença constitutiva deles vai além da questão clínica de diferentes graus de perda auditiva, como os leigos e estudiosos (que desconhecem a língua de sinais brasileira) afirmam, e é ela - enquanto marca linguística e cultural - que vai perpetuá-los até o fim da existência.

\section{Considerações Finais}

Este artigo mostra a possibilidade da existência do território marcado pelos Jovens Surdos, com suas gírias em sinais, um dos aspectos marcantes da Cultura Surda. Apresentamos, de forma breve, as 12 (doze) gírias em sinais dos Jovens Surdos, sem contar com os aspectos 
da palavra Juventude. Também analisamos os aspectos da cultura Surda, que envolvem a criação de gírias em sinais, muito utilizadas pelos diferentes grupos.

Por fim, apresentamos 12 (doze) gravuras com suas traduções para entender os significados de cada mensagem. Não podemos deixar de pensar que as gírias em sinais que ocorreram na década de 80 (oitenta) até a presente data, para o enriquecimento lexical e a preservação da Libras no território brasileiro, contribuem para a produção de conhecimentos e o respeito da identidade e da cultura surda.

\section{Agradecimentos:}

Aos Professores Surdos e ex-alunos do INES:

Rejane Silveira

Marlene Pereira do Prado

Weslei Rocha

\section{REFERÊNCIAS}

CECILIO, Gilmara; SOUZA, Camilo. Identidades Transitantes: o desencaixe do deficiente auditivo nos discursos de/sobre surdos e ouvintes. Revista Virtual de Cultura Surda e Diversidade. Disponível em: 〈http://www.editora-arara-azul.com.br/revista/compar5.php〉. Acesso em 20 de jun. 2016.

DORZIAT, A. O outro da educação: pensando a surdez com base nos temas identidade/diferença, currículo e inclusão. Petrópolis, RJ: Vozes, 2009.

FERNANDES, S. Educação de surdos. 2.ed. Atual. Curitiba: Ibpex, 2011.

GÍRIAS dos anos de 60 a 90. Disponível em: https://fiquepastel.wordpress.com/2009/11/16/girias-anos-60-a-90/ Acesso em: 20 jun 2016.

HALL, Stuart. The spectacle of the other. In: HALL, Stuart. Representation. Cultural representations and signifyng practises. Londres: Thousand Oaks, 1997. P. 223-290 HONÓRIO, Ricardo. Concepção da Cultura. s/d Disponível em: <http://www.antropologia.com.br/divu/colab/d12-rhonorio.pdf>. Acesso em: 23 jun. 2016.

MANDELLI, Maria Teresa et. alli. Juventude e projeto de vida: novas perspectivas em orientação profissional. Arquivos Brasileiros de Psicologia, n. 63, 2011. Disponível em: <http://seer.psicologia.ufrj.br/index.php/abp/article/view/723/587>. Acesso em: 20 jun 2016.

MORESI, Eduardo (org.). Metodologia da Pesquisa. Programa De Pós-Graduação Stricto Sensu Em Gestão Do Conhecimento e Tecnologia da Informação: UNB. Mar. 2003. 
PERLIN, G.; MIRANDA, Wilson. Surdos: o narrar e a política. Florianópolis: Ponto de Vista (UFSC), vol. 5, 2003. p. 217-226.

PERLIN, Gladis. As Identidades Surdas. Revista da FENEIS, Ano IV, n. 14 abr./jun. de 2002.

QUADROS, Ronice; PERLIN, Gladis. Estudos Surdos III. IN: SCHMITT, Deonisio. Espaço de Conforto Linguístico/Cultural dos Surdos na UFSC. Petrópolis: Arara Azul, 2005.

SANTOS FILHO, Genivaldo; OLIVEIRA, Rozilda. Os Desafios na Comunicação entre os Surdos e a família. Disponível em: <http://www.webartigos.com/artigos/os-desafios-nacomunicacao-entre-os-surdos-e-a-familia/31113/\#ixzz4CiZhThmA>. Acesso em: 20 jun 2016.

SANTOS, Caroline Reis Vieira. Tradução de Gírias em Harry Potter: um estudo com base em Corpus. Tese de Doutorado. Programa de Estudos de Tradução: Florianópolis, UFSC. 2014.

SILVA, Glaúcia Faria da. Reflexões psicanalíticas sobre a língua, o estrangeiro e a intimidade em casos de surdez profunda. Revista Psicologia da America Latina: Mexico. Abril 2007. n. 9. Disponível em: <http://pepsic.bvsalud.org/scielo.php?script=sci_arttext\&pid=S1870350X2007000100011> Acesso em: 20 jun 2016.

\footnotetext{
${ }^{\text {i }}$ Professora Doutora do Curso de Pedagogia Bilíngue do Departamento de Ensino Superior do Instituto Nacional de Educação de Surdos.

ii Utilizaremos a sigla Libras para nos referir à Língua Brasileira de Sinais, escrita apenas com a letra inicial maiúscula, conforme a lei 10.436/02 e o decreto 5.626/05.

iii Quando nos referirmos aos "Surdos ou Surdas", sempre escreveremos com inicial maiúscula, pois, embasado em Dorziat (2009), buscamos marcar uma concepção política de surdez vista para além do fator biológico ou clínico-terapêutico. Não utilizaremos o termo "pessoa com surdez", pois, segundo Fernandes (2011), o termo surdez refere-se a aspectos clínico-terapêuticos relacionados à perda auditiva e à deficiência.

iv Franklin Goldgrub (apud SILVA, 2007) lança a hipótese de que o fato de ser uma língua aprendida "artificialmente" revestiria as línguas de sinais de "efeitos menos cruciais", pode-se mesmo dizer estrangeira (em relação à língua materna - este qualificativo é significativo) para o sujeito.

v Signo de identificação do grupo (SILVA, 2014).

${ }^{\text {vi }}$ Conceito de Hall, 1997.
} 